\title{
STRATEGI INOVASI SEBAGAI UPAYA PENGEMBANGAN USAHA FROZEN FOOD DI MASA PANDEMI
}

\author{
Rika Septiani Wahyudi ${ }^{1}$, Galih Crysta Mentari ${ }^{2)^{*}}$, Nanik Kustiningsih ${ }^{3)}$ \\ 1) rikaseptiani452@gmail.com; Jurusan Akuntansi STIE Mahardhika \\ 2) g.crystamentari@gmail.com; Jurusan Akuntansi STIE Mahardhika \\ 3) nanik@stiemahardhika.ac.id; Jurusan Akuntansi STIE Mahardhika \\ * penulis korespondensi
}

\begin{abstract}
This study aims to analyze the business strategy of LELEKU.ID Frozen Food during the covid-19 pandemic through a SWOT (Strength, Weakness, Opportunity, Treath) analysis approach. This research uses descriptive qualitative methods and interviews, collects the latest information, identifies social problems, especially those related to the economy and covid-19, and identifies business actors due to the covid-19 pandemic. Determination of the strategy used in this study using three stages of strategy formulation analysis which ultimately resulted in alternative priority strategies. The results of this study indicate that the strategy used by LELEKU.ID Frozen Food is to innovate with various processed catfish products, and not to use harmful ingredients and is safe for consumption. The main alternative strategy chosen by LELEKU.ID Frozen Food is to include social media addresses on the sticker on the packaging which can increase consumer confidence in consuming business products. This strategy can increase competitive advantage among MSMEs in today's uncertain conditions.
\end{abstract}

Keywords: Innovation, MSME, Strategic Management, SWOT

\begin{abstract}
Abstrak
Penelitian ini bertujuan untuk menganalisis strategi bisnis dari LELEKU.ID Frozen Food pada masa pandemi covid-19 melalui pendekatan analisis SWOT (Strength, Weakness, Opportunity, Treath). Penelitian ini menggunakan metode deskriptif kualitatif dan wawancara, mengumpulkan informasi terkini, mengidentifikasi masalah sosial khususnya terkait ekonomi dan covid-19, serta mengidentifikasi pelaku usaha karena adanya pandemi covid-19. Penentuan strategi yang digunakan pada penelitian ini yaitu menggunakan tiga tahap analisis formulasi strategi yang akhirnya menghasilkan alternatif strategi prioritas. Hasil penelitian ini menunjukkan bahwa strategi yang digunakan LELEKU.ID Frozen Food yaitu berinovasi dengan berbagai olahan produk dari ikan lele, serta tidak menggunakan bahan berbahaya dan aman dikonsumsi. Alternatif utama strategi yang dipilih oleh LELEKU.ID Frozen Food mencantumkan alamat media sosial di sticker pada kemasan yang dapat meningkatkan kepercayaan konsumen dalam mengonsumsi produk usaha. Strategi ini dapat meningkatkan keunggulan bersaing antar UMKM di kondisi yang tidak menentu seperti saat ini.
\end{abstract}

Kata kunci: Inovasi, Manajemen Stratejik, SWOT, UMKM

\section{PENDAHULUAN}

Frozen food merupakan salah satu usaha yang mulai digemari serta memiliki prospek cukup baik, sehingga banyak pelaku usaha yang memilih untuk memproduksi dan menjualnya. Hasil dari survei yang dilaksanakan oleh Kementerian Pertanian (2015) (Santoso et al.,2018), yaitu tingkat permintaan dalam konsumsi olahan daging berkembang sangat pesat di Indonesia dengan rata-rata 10,28 persen tiap tahunnya. Frozen food menjadikan produk olahan terbuat dari daging yang sering dikonsumsi masyarakat. LELEKU.ID Frozen Food merupakan usaha kecil rumah tangga yang bergerak pada bidang olahan makanan yaitu nugget dan bakso yang terbuat dari ikan lele. Usaha ini terbentuk atas tingginya minat masyarakat yang suka dengan makanan instan, salah satunya yaitu frozen food sebagai pendamping nasi maupun camilan. Menurut Muhani et al. (2020), UMKM (Usaha Mikro Kecil Menengah) mulai memproduksi produk yang diminati masyarakat selama masa pandemi, sedangkan bagi para pelaku usaha bidang kuliner diharapkan dapat menyiapkan makanan berbentuk frozen food, makanan siap masak, dan makanan siap dimakan. Seorang pebisnis dituntut menjadi seorang yang inovatif yang dapat menciptakan ide-ide dan strategi untuk mengembangkan bisnis yang dimiliki.

Inovasi merupakan strategi untuk menciptakan sesuatu baru yang berbeda dari sebelumnya (Amalia Arista, Indah Yuliana \& Nanik, K. (2021)). LELEKU.ID Frozen Food 
bermula dari kegiatan kewirausahaan mahasiswa STIE Mahardhika Surabaya yang terbentuk sejak Oktober 2021 yang kemudian melakukan inovasi dengan membuat ide bisnis produk olahan makanan yang terbuat dari ikan lele. Mungkasa (2020) menyatakan bahwa bekerja dari rumah (Work From Home) merupakan salah satu konsep dari bekerja jarak jauh (telecommuniting). Selama pandemi covid-19, pemerintah maupun swasta menerapkan skema ini sehingga banyak kegiatan seperti pembelajaran, pekerjaan, dan unit usaha yang berkontak langsung terhambat bahkan terhenti selama pandemi. Hal ini diperkuat dengan hasil survei yang dilakukan oleh Lembaga Ilmu Pengetahuan Indonesia (LIPI). Humas LIPI menyatakan bahwa selama pandemi hampir 95\% usaha di Indonesia mengalami penurunan penjualan. Dilihat dari skala usaha, lebih dari $40 \%$ usaha ultra-mikro, mikro, kecil, dan menengah mengalami penurunan penjualan diatas $75 \%$. Langkah dalam meminimalisir risiko jangka pendek yang dialami oleh UMKM selama pandemi adalah menciptakan stimulus pada sisi permintaan serta memacu UMKM untuk memperluas kemitraan dengan platform online (Nugroho, 2020).

Berdasarkan hasil survei tersebut, banyak usaha mengalami kerugian terutama di bidang UMKM sehingga langkah yang ditempuh dalam mengatasi hal ini yaitu mulai berganti melakukan aktivitas penjualan berbasis online, salah satunya pada usaha LELEKU.ID Frozen Food. Dengan keadaan seperti ini, strategi manajemen yang diperlukan LELEKU.ID Frozen Food yaitu mengidentifikasi faktor eksternal dan internal yang bertujuan untuk meningkatkan keunggulan bersaing antar UMKM di masa pandemi covid-19. Evaluasi lingkungan eksternal dan internal dapat dilakukan dengan melakukan analisa SWOT untuk melihat dan memahami ancaman, tantangan, peluang, dan hambatan yang terjadi dimasa pandemi covid-19. Tujuan penelitian ini adalah untuk menganalisis strategi bisnis LELEKU.ID Frozen Food dengan pendekatan analisis SWOT (Strength, Weakness, Opportunity, Treath) untuk mengidentifikasi terhadap faktor internal dan eksternal. Hasil dari analisis SWOT dipilih dengan menentukan nilai tertimbang dalam perumusan strategi sehingga dapat menghasilkan matriks SWOT. Hasil matriks SWOT ini untuk mengevaluasi kekuatan, kelemahan, peluang, dan ancaman pada usaha LELEKU.ID Frozen Food yang menghasilkan solusi dan strategi dalam menghadapi penjualan di era covid-19.

\section{KAJIAN PUSTAKA}

Menurut Rangkuti (Ramadhan \& Sofiyah, 2013), strategi merupakan perencanaan dalam pengoperasian dan pengalokasian sumber daya yang penting untuk memperoleh tujuan jangka panjang suatu perusahaan. David dan David (2016:11) mengatakan strategi merupakan aktivitas dalam skala besar yang memerlukan keputusan dari manajemen tingkat atas dan sumber daya yang dimiliki perusahaan (Prastiti et al., 2018). Dari kedua teori tersebut strategi adalah kumpulan dari rencana atau tindakan oleh manajemen dan sumber daya perusahaan untuk mencapai tujuan jangka panjang perusahaan.

Manajemen strategik (strategic management) adalah seni dan ilmu dalam merencanakan atau merumuskan, menerapkan, dan mengevaluasi keputusan dari beberapa segi fungsional perusahaan untuk memperoleh tujuan jangka panjang. Tujuan dari manajemen strategik yaitu mendapatkan dan membuat peluang baru yang berbeda untuk perumusan jangka panjang (long-range planning), sebaliknya mencoba untuk memaksimalkan tren masa depan yang mengacu pada tren masa kini (David \& David, 2017). Selain itu, menurut Stephen P.Robbins-Mary Coulter (Seputro, 2019) manjemen strategik merupakan bentuk tindakan untuk mengembangkan strategi organisasi yang dilakukan oleh manager dengan melibatkan beberapa fungsi antara lain dasar-perencanaan, pengorganisasian, memimpin, dan pengendalian.

Manajemen strategi memiliki3 tahapan antara lain formulasi, implementasi, dan evaluasi strategi (David \& David, 2017). Proses manajemen strategi memerlukan analisis 
lingkungan eksternal (hal yang terjadi di luar perusahaan) dan internal (hal yang terjadi di dalam perusahaan). Tujuan analisis lingkungan adalah menginterpretasikan lingkungan organisasi sehingga manajemen mampu menanggapi dan merespon berbagai perubahan dan isu kritis yang cukup berpengaruh terhadap perusahaan (Juwono, 2012). Dengan analisis lingkungan dapat menyediakan suatu informasi dalam lingkungan perusahaan untuk mengidentifikasi kekuatan, kelemahan, peluang dan ancaman.

Menurut Rangkuti (2006) (Rahmayati, 2015) SWOT merupakan akronim dari strength dan weaknesses yang berarti kekuatan dan kelemahan terletak pada lingkungan internal serta opportunity dan threats yang berarti peluang dan ancaman yang terletak pada lingkungan eksternal. Analisis SWOT digunakan sebagai pembanding antara faktor internal (kekuatan dan kelemahan) dengan faktor eksternal (peluang dan ancaman). Analisa SWOT didasarkan pada asumsi bahwa dari faktor internal dan eksternal dapat menjadi strategi yang efektif dengan meminimalisir kelemahan dan ancaman serta memaksimalkan kekuatan dan peluang (Noor, 2014). Jika analisis ini diimplementasikan secara akurat dapat memiliki dampak yang cukup besar atas rancangan alternatif strategi yang dihasilkan.

\section{METODE PENELITIAN}

Metode yang digunakan dalam analisis strategi LELEKU.Id Frozen Food ialah metode deskriptif kualitatif dan wawancara, mengumpulkan informasi terkini, mengidentifikasi masalah sosial khususnya terkait ekonomi dan covid-19, dan mengidentifikasi pelaku usaha karena adanya pandemi covid-19. Pengumpulan data dilakukan dengan observasi dengan wawancara terhadap pelaku usaha, selanjutnya melakukan identifikasi faktor internal dan eksternal dengan menerapkan analisis SWOT berupa faktor kekuatan, kelemahan, peluang, dan ancaman usaha LELEKU.Id Frozen Food. Penyusunan SWOT ini dilakukan dengan pemberian skor untuk mengetahui bobot tertimbang setiap kriteria dalam menetapkan strategi terpilih.

Tabel 1. Skema Analisa Formulasi Strategi

\begin{tabular}{|c|c|c|c|}
\hline \multicolumn{5}{|c|}{ TAHAP 1: TAHAP INPUT } \\
\hline $\begin{array}{c}\text { Matriks Eksternal Factor } \\
\text { Evaluation (EFE) }\end{array}$ & $\begin{array}{c}\text { Matriks Internal Factor } \\
\text { Evaluation (IFE) }\end{array}$ & $\begin{array}{c}\text { Competitive Profile Matrix } \\
\text { (CPM) }\end{array}$ \\
\hline \multicolumn{5}{|c|}{ TAHAP 2: TAHAP PENCOCOKAN } & $\begin{array}{c}\text { Matriks } \\
\text { Strategy }\end{array}$ \\
\hline Matriks SWOT & $\begin{array}{c}\text { Matriks } \\
\text { Strategic } \\
\text { Position and } \\
\text { Action } \\
\text { Evaluation } \\
\text { (SPACE) }\end{array}$ & $\begin{array}{c}\text { Matriks Boston } \\
\text { Consulting } \\
\text { Internal (IE) }\end{array}$ & \\
\hline \multicolumn{4}{|c|}{ TAHAP 3: TAHAP KEPUTUSAN } \\
\hline
\end{tabular}

Sumber: (David \& David, 2017)

Teknik penyusunan strategi dapat dikombinasikanke dalam tiga kerangka pembuatan keputusan, yaitu: tahap 1 (tahap input) terdiri dari Matriks EFE (Eksternal Factor Evaluation), Matriks IFE (Internal Factor Evaluation), dan Competitive Profile Matrix (CPM), tahap 2 (tahap pencocokan) terdiri dari Matriks SWOT, Matriks Boston Consulting Group (BCG), Matriks Strategic Position and Action Evaluation (SPACE), Matriks Grand Strategy, dan Matriks Eksternal-Internal (IE), tahap 3 (tahap keputusan) menggunakan Quantitative Strategic Planning Matrix (QSPM) (David \& David, 2017). 
Tabel 2. Matriks SWOT

\begin{tabular}{|l|l|l|}
\hline Internal/Eksternal & Strenght (S) & Weakness (W) \\
& 1. & 1. \\
& 2. & 2. \\
\hline Threat (T) & Strategi ST & Startegi WT \\
1. & Menggunakan S untuk & Meminimalkan W dan \\
2. & menghindari $T$ & menghindari T \\
\hline Opportunity (O) & Strategi SO & Strategi WO \\
1. & Menggunakan $S$ untuk & Mengatasi W dengan \\
2. & memanfaatkan $O$ & memanfaatkan O \\
\hline
\end{tabular}

Sumber : (Narto \& Basuki, 2020)

Penyusunan faktor internal dan eksternal disusun dengan matriks IFE (Internal Factor Evaluation) dan EFE (External Factor Evaluation) seperti pada tabel 3 dan tabel 4. Selanjutnya tahap pencocokan menggunakan penyusunan matriks SWOT yang menimbulkan empat alternatif strategi yaitu strategi ST (Strength-Threats), WT (Weakness-Threats), SO (StrengthOpportunities), dan WO (Weakness-Opportunities) seperti pada tabel 5. Tahap terakhir adalah mengambil keputusan strategi menggunakan QSPM yang terdapat pada tabel 6 .

\section{HASIL DAN PEMBAHASAN}

Hasil wawancara terhadap pemilik UMKM LELEKU.ID frozen food digunakan untuk menyusun faktor-faktor SWOT (Strength, Weakness, Opportunity, Treath)usaha LELEKU.ID Frozen Food. Usaha LELEKU.ID Frozen Food dimulai pada tahun 2021 karena adanya program kewirausahaan mahasiswa STIE Mahardhika Surabaya dan masih berlangsung hingga saat ini. Karena terbentuknya usaha ini di tengah pandemi COVID-19 maka penjualan dan pemasaran dilakukan secara online. Untuk itu LELEKU.ID memanfaatkan berbagai media sosial seperti instagram, tokopedia dsb. Produk LELEKU.ID terdiri dari berbagai varian olahan makanan yang terbuat dari ikan lele, seperti nugget dan bakso.

\section{Tahap Input}

Analisis Internal-Eksternal ini digunakan untuk mengukur kinerja objek dengan menentukan skor yang didapat dari penilaian lingkungan usaha LELEKU.ID Frozen Food. Skala penilaian faktor positif (Strenght dan Opportunity) adalah sebagai berikut: sangat lemah diberi nilai 1, lemah diberi nilai 2, kuat diberi nilai 3, dan sangat kuat diberi nilai 4. Sementara itu, skala penilaian negatif (Weakness dan Threat) yaitu: sangat kuat diberi nilai 1, kuat diberi nilai 2, lemah diberi nilai 3, dan sangat lemah diberi nilai 4. Jumlah dari keseluruhan bobot adalah 10,0. Berdasarkan hasil penelitian, wawancara narasumber, dan observasi diperoleh data seperti pada tabel 3 dan tabel 4 sebagai berikut:

\section{a. Matriks IFE}

Analisis lingkungan internal (IFE) berfungsi untuk mengidentifikasi kemungkinan kekuatan dan kelemahan (Subaktilah et al., 2018). Tingkat kekuatan dan kelemahan usaha LELEKU.ID Frozen Food diketahui melalui rating dan pembobotan terhadap unsur lingkungan internal usaha sebagai evaluasi tingkat pengaruh bagi pengembangan usaha. 
Tabel 3. Matriks IFE LELEKU.ID Frozen Food

\begin{tabular}{|c|l|l|l|}
\hline Faktor internal & Bobot & Rating & Skor \\
\hline Kekuatan & & & \\
\hline 1. Banyak peminat makanan frozen food & 0.05 & 1 & 0.05 \\
\hline 2. Harga terjangkau (lebih murah) & 0.11 & 3 & 0.33 \\
\hline $\begin{array}{l}\text { 3. Produk tidak mengandung bahan } \\
\text { pengawet }\end{array}$ & 0.16 & 4 & 0.64 \\
\hline 4. Varian produk beragam & 0.11 & 3 & 0.33 \\
\hline 5. Bahan baku berkualitas & 0.12 & 3 & 0.36 \\
\hline Kelemahan & & & 0.64 \\
\hline $\begin{array}{l}\text { Minimnya pengalaman bidang } \\
\text { pemasaran }\end{array}$ & 0.16 & 4 & 0.12 \\
\hline $\begin{array}{l}\text { Merk dagang belum banyak diketahui } \\
\text { 3. Membutuhkan daya listrik yang tinggi } \\
\text { untuk mesin pendingin atau freezer }\end{array}$ & 0.06 & 2 & 0.05 \\
\hline $\begin{array}{l}\text { Produk tidak tahan lama karena tanpa } \\
\text { pengawet }\end{array}$ & 0.10 & 3 & 0.30 \\
\hline $\begin{array}{l}\text { Jumlah SDM yang masih terbatas dan } \\
\text { belum banyak pengalaman }\end{array}$ & 0.08 & 2 & 0.16 \\
\hline$\quad$ Jumlah & 1.00 & & 2.98 \\
\hline
\end{tabular}

Bagan matriks IFE pada tabel 3 mengindikasikan nilai Internal Factor Evaluation (IFE) sebesar 2,98 atau jika dibulatkan ke atas menjadi 3 (kuat). Angka ini menunjukkan bahwa pengaruh internal seperti kekuatan dan kelemahan produk berpengaruh kuat terhadap produk LELEKU.ID Frozen Food. Rating pada angka 4 menunjukkan faktor tersebut sangat kuat memengaruhi produk. Faktor yang menjadi kekuatan utama LELEKU.ID Frozen Food adalah produk yang tidak mengandung bahan pengawet memiliki nilai tertimbang tertinggi sebesar 0,64 dan minimnya pengalaman bidang pemasaran owner produk pada faktor internal kelemahan (Weakness) dengan nilai tertimbang sebesar 0,64.

\section{b. Matriks EFE}

Analisis lingkungan eksternal (EFE) berfungsi untuk mengidentifikasi kemungkinan peluang dan ancaman. Tingkat peluang dan ancaman usaha LELEKU.ID Frozen Food diketahui melalui rating dan pembobotan terhadap unsur lingkungan eksternal sebagai evaluasi tingkat pengaruh bagi pengembangan usaha. 
Tabel 4. Matriks LELEKU.ID Frozen Food

\begin{tabular}{|c|c|c|c|}
\hline Faktor Internal & Bobot & Rating & Skor \\
\hline \multicolumn{4}{|l|}{ Peluang } \\
\hline 1. Pangsa pasar yang cukup luas & 0.16 & 4 & 0.64 \\
\hline $\begin{array}{l}\text { 2. Harga bahan baku terjangkau dan modal } \\
\text { tidak terlalu besar. }\end{array}$ & 0.07 & 2 & 0.14 \\
\hline $\begin{array}{l}\text { 3. Karena tanpa bahan kimia, produk ini } \\
\text { bisa dikonsumsi terus menerus secara } \\
\text { berkala }\end{array}$ & 0.10 & 3 & 0.30 \\
\hline $\begin{array}{l}\text { 4. Masyarakat berninat mencoba berbagai } \\
\text { varian produk sehingga penjualan dapat } \\
\text { meningkat }\end{array}$ & 0.11 & 3 & 0.33 \\
\hline $\begin{array}{l}\text { 5. Produk yang terbuat dari bahan baku } \\
\text { yang masih jarang dibuat, } \\
\text { sehinggamembuat produk unik. }\end{array}$ & 0.12 & 3 & 0.36 \\
\hline \multicolumn{4}{|l|}{ Ancaman } \\
\hline 1. Tidak selalu ramai & 0.15 & 4 & 0.14 \\
\hline $\begin{array}{l}\text { 2. Keyakinan masyarakat untuk membeli } \\
\text { produk kecil }\end{array}$ & 0.07 & 2 & 0.14 \\
\hline $\begin{array}{l}\text { 3. Untuk pengiriman ke luar kota/pulau } \\
\text { masih beresiko karena tampa bahan } \\
\text { pengawet }\end{array}$ & 0.10 & 3 & 0.30 \\
\hline 4. Persaingan yang semakin banyak & 0.10 & 3 & 0.30 \\
\hline $\begin{array}{l}\text { 5. Pasar produk masih disekitar tempat } \\
\text { produksi dan sekitarnya. }\end{array}$ & 0.05 & 1 & 0.05 \\
\hline Jumlah & 1.00 & & 3.00 \\
\hline
\end{tabular}

Bagan matriks EFE pada tabel 4 mengindikasikan nilai External Factor Evaluation (EFE) sebesar 3 (kuat). Hal ini menunjukkan faktor eksternal kuat mempengaruhi produk LELEKU.ID frozen food, baik peluang dan ancaman. Rating pada angka 4 meunjukkan faktor tersebut sangat kuat memengaruhi produk. Faktor yang menjadi peluang utama perusahaan ialah pangsa pasar yang cukup luas denganbobot tertinggi sebesar 0,64 dan produk yang tidak selalu laku/ramai pada faktor enternal ancaman (Threat) dengan nilai tertimbang sebesar 0,60. Untuk dapat mengetahui strategi apa yang lebih tepat digunakan, maka dilakukanlah tahap pencocokan.

\section{Tahap Pencocokan}

Tahap ini digunakan untuk merencanakan strategi berdasarkan hasil identifikasi dan analisis dari faktor lingkungan perusahaan (faktor eksternal dan internal) yang telah dihimpun (Ramadhan \& Sofiyah, 2013). Dalam perumusan strategi tahap pencocokan ini yaitu menggunakan matriks SWOT. Hasil pengimputan SWOT melalui matriks IFE dan EFE ini dapat diformulasikan dengan menghasilkan empat kategori kemungkinan alternatif strategi. Analisis matriks SWOT dapat dilihat pada Tabel 5. 
Tabel 5. Matriks SWOT LELEKU.ID Frozen Food

\begin{tabular}{|c|c|c|}
\hline Internal/Eksternal & $\begin{array}{l}\text { Strenght }(S) \\
\text { 1. Banyak peminat makanan } \\
\text { frozen food } \\
\text { 2. Harga terjangkau (lebih } \\
\text { murah) } \\
\text { 3. Produk tidak mengandung } \\
\text { bahan pengawet } \\
\text { 4. Varian produk lebih } \\
\text { beragam } \\
\text { 5. bahan baku berkualitas }\end{array}$ & $\begin{array}{l}\text { Weakness }(\mathrm{W}) \\
\text { 1. Minimnya pengalaman } \\
\text { bidang pemasaran } \\
\text { 2. Merk dagang belum } \\
\text { banyak diketahui } \\
\text { 3. Membutuhkan daya listrik } \\
\text { yang tinggi untuk mesin } \\
\text { pendingin atau freezer. } \\
\text { 4. Produk tidak tahan lama } \\
\text { karena tanpa pengawet } \\
\text { 5. Jumlah SDM yang masih } \\
\text { terbatas dan belum banyak } \\
\text { pengalaman }\end{array}$ \\
\hline
\end{tabular}

\section{Threat $(\mathrm{T})$}

1. Tidak selalu laku/ramai

2. Keyakinan masyarakat untuk membeli produk kecil 3. Untuk pengiriman di luar kota/pulau masih berisiko karena makanan tanpa bahan pengawet

4. Persaingan yang semakin banyak.

5. Pasar produk masih di sekitar tempat produksi dan sekitarnya

\section{Strategi ST}

Menggunakan S untuk menghindari $T$

1. Mempertahankan kestabilan harga produk dengan membatasi kuantitas produksi. (S1, S2 - T1, T2, T3)

2. Berinovasi dengan varian baru dan tetap menjaga kualitas produk tetap sama (S4 - T4)

\section{Menggunakan} pengemasan kotak plastik/ kedap udara (S3, S5)
1. Pangsa pasar yang cukup luas

2. Harga bahan baku terjangkau dan modal tidak membutuhkan pinjaman membuat produk banyak diminati dan terhindar dari pelunasan hutang 3. Karena tanpa bahan kimia, produk ini bisa

\section{Startegi WT \\ Meminimalkan $W$ dan menghindari $T$}

1. Memposting produk dan review konsumen di sosial media official dan tim produksi dan pemasaran secara berkala (W1, W2 T1, T2, T4, T5)

2. Menggunakan harga setelah bahan baku telah dihitung BOP dan berinovasi menggunakan bahan alami yang dapat dijadikan bahan pengawet alami (W3, W4, T3)

3. Mengadakan atau mengikuti pelatihan UMKM untuk menambah pengalaman (W5)

Strategi WO

Mengatasi $W$ dengan memanfaatkan $O$

1. Menggunakan sosial media sebagai wadah promosi agar cakupan pasar produk luas (W1, W2, O1, O5)

2. Menghitung BOP serta biaya tambahan agar tidak sebagai pertimbangan konsumsi konsumen (S4, bahan berbahaya dan bisa dikonsumsi terus menerus

O4)

3. Tidak menggunakan 


\begin{tabular}{|l|l|l|}
\hline $\begin{array}{l}\text { dikonsumsi terus-menerus } \\
\text { secara berkala }\end{array}$ & $\begin{array}{l}\text { menimbulkan kerugian (W3, } \\
\text { O2) } \\
\text { 3. Berinovasi dengan bahan } \\
\text { alami sebagai bahan } \\
\text { pengawet non kimia dan }\end{array}$ \\
\hline $\begin{array}{l}\text { 4. Masyarakat berminat } \\
\text { untuk mencoba berbagai } \\
\text { varian produk sehingga } \\
\text { penjualan dapat meningkat } \\
\text { 5. Produk yang terbuat dari } \\
\text { bahan baku yang masih } \\
\text { jarang dibuat, sehingga } \\
\text { membuat produk unik. }\end{array}$ & $\begin{array}{l}\text { (S3, O3) } \\
\text { bahan baku serta } \\
\text { pengemasan agar tidak } \\
\text { membutuhkan banyak biaya } \\
\text { tambahan (S2, O2) }\end{array}$ & $\begin{array}{l}\text { mengadakan pelatihan untuk } \\
\text { pekerja (W4, W5, O3, O4) }\end{array}$ \\
\hline
\end{tabular}

\section{Strategi ST (kekuatan-ancaman)}

Strategi ST (kekuatan-ancaman) digunakan untuk mengatasi ancaman dengan menggunakan kekuatan internal LELEKU.Id Frozen food. Strategi ST memiliki tiga alternatif strategi. Alternatif strategi pertama yaitu mempertahankan kestabilan harga produk dengan membatasi kuantitas produksi. Produk LELEKU.Id Frozen food merupakan produk tanpa bahan pengawet sehingga jangka waktu aman dikonsumsi cukup pendek.

Strategi ini digunakan dengan cara memproduksi pada saat persediaan produk menipis sehingga kualitas produk tetap terjaga. Tahap produksi dilakukan dengan mengecek persediaan yang ada di freezer, owner tidak memiliki jadwal tetap untuk produksi karena bergantung pada penjualan. Selain itu, LELEKU.Id Frozen Food harus tetap mempertahankan kestabilan harga produk, karena konsumen cenderung menginginkan makanan yang lebih murah dengan kualitas yang baik. Alternatif strategi kedua yaitu berinovasi dengan varian produk baru dan tetap menjaga kualitas produk tetap sama. Strategi ini digunakan untuk memberi cita rasa baru dengan harapan dapat menarik minat masyarakat untuk membeli produk LELEKU.Id Frozen Food. Seiring dengan inovasi tersebut, produsen juga tetap harus menjaga kualitas produk tetap sama.

Alternatif strategi ST yang terakhir yaitu menggunakan pengemasan kotak plastik/ kedap udara. Strategi ini digunakan apabila terdapat pembelian produk berasal dari luar kota dengan menggunakan jasa pengiriman. Pemberian kotak plastik/kedap udara ini bertujuan untuk menjaga umur masa produk saat pengiriman.

\section{Strategi WT (kelemahan-ancaman)}

Strategi WT (kelemahan-ancaman) digunakan untuk meminimalisir kelemahan dan menghindari ancaman usaha LELEKU.Id Frozen Food. Strategi WT memiliki dua alternatif strategi. Strategi ini digunakan untuk meminimalisir kelemahan dan menghindari ancaman usaha LELEKU.Id Frozen Food. Strategi WT yang pertama yaitu memposting produk dan review konsumen di sosial media official dan para pekerja secara berkala. Tidak dapat dipungkiri bahwa kepercayaan konsumen akan produk yang ditawarkan berpengaruh penting dalam usaha/bisnis. Produsen juga mengharapkan feedback positif yang diterima dari konsumen dapat menarik perhatian calon konsumen sehingga setidaknya ingin mencoba produk tersebut.

Strategi WT kedua yaitu menggunakan harga setelah bahan baku telah dihitung BOP dan berinovasi menggunakan bahan alami yang dapat dijadikan bahan pengawet alami. 
Ketersediaan bahan baku yang tidak selalu ada terkadang menjadikan produsen kesulitan untuk menentukan harga yang pas. Strategi ini mengutamakan agar tim produsen mengetahui banyak biaya yang dikeluarkan serta mengetahui perkiraan laba yang akan diterima. Perhitungan ini juga dapat mengkalkulasi ancaman kerugian sewaktu-waktu jika produk mengalami kerusakan atau kurang laku di pasaran.

\section{Strategi SO (Kekuatan-Peluang)}

Strategi SO (kekuatan-peluang) menggunakan strategi kekuatan internal untuk memperoleh manfaat dari peluang LELEKU.IdFrozen Food. Strategi SO memiliki tigat alternatif strategi. Pertama, memiliki varian produk sebagai pertimbangan konsumsi konsumen.

Konsumen tentu saja berkeinginan untuk mencoba hal baru jika sudah mulai bosan dengan yang biasa dikonsumsi. Oleh sebab itu, strategi dengan menambah atau memiliki varian produk yang lain dapat menjadi daya tarik konsumen untuk mencoba produk tersebut. Strategi kedua yaitu tidak menggunakan bahan berbahaya dan bisa dikonsumsi terus menerus. Selama ini masyarakat beranggapan bahwa frozen food pasti menggunakan bahan pengawet atau bahan berbahaya lainnya. Selain itu, frozen food masih erat kaitannya dengan makanan yang minim manfaat bila dikonsumsi. Startegi ini dapat membuktikan bahwa frozen food tidak selamanya berdampak buruk bagi kesehatan.

Strategi SO terakhir yaitu bahan baku terjangkau serta pengemasan tidak membutuhkan banyak biaya tambahan. Bahan baku yang digunakan dalam produk tersebut tidak sulit dijumpai di sekitar pasaran sehingga produsen tidak memerlukan biaya perolehan tambahan untuk bahan baku. Kemasan yang digunakan produk pun mudah dijumpai sehingga biaya perolehan untuk kemasan pun bisa diminimalisir.

\section{Strategi WO (Kelemahan-Peluang)}

Strategi WO (kelemahan-peluang) digunakan untuk mengatasi kelemahan dengan memanfaatkan peluang usaha LELEKU.IdFrozen Food. Strategi WO memiliki dua alternatif strategi. Pertama, menggunakan sosial media sebagai wadah promosi agar cakupan pasar produk luas.Media sosial sendiri adalah sebuah media daring yang dipakai masyarakat agar mempermudah berinteraksi jarak jauh. Dengan menggunakan media sosial, Strategi ini dapat digunakan untuk menyampaian informasi mengenai produk kepada konsumen agar produk LELEKU.Id Frozen Food lebih dikenal oleh masyarakat.

Alternatif strategi kedua yaitu menghitung BOP (Biaya Operasional Perusahaan) serta biaya tambahan agar tidak menimbulkan kerugian. Menghitung BOP serta biaya tambahan memiliki peran yang sangat penting pada kelangsungan hidup bisnis maupun perusahaan. Maka dari itu, strategi ini sangat dibutuhkan untuk berjalanannya suatu bisnis usaha.

\section{Kuadran SWOT}

Tahap selanjutnya adalah memilih salah satu dari keempat komponen strategi dengan melihat posisi bisnis LELEKU.Id Frozen Food. Pemilihan posisi bisnis dapat dilakukan dengan menggunakan kuadran SWOT. Dalam pembuatan kuadran SWOT terdapat 4 sisi kuadran, yaitu kuadran I menggambarkan letak perusahaan berada pada strategi S-O (strength-opportunity), kuadran II terletak pada strategi W-O (weakness-opportunity), dan kuadran III terletak pada strategi W-T (weakness-threat), serta kuadran IV terletak pada strategi S-T (strength-threat) (Baroto \& Purbohadiningrat, 2014). Selanjutnya menentukan koordinat sumbu X dan sumbu Y dari nilai tertimbang matriks IFE dan matriks EFE. Sumbu $X$ adalah nilai tertimbang dari matriks IFE sebesar 2,98, sedangkan sumbu Y adalah nilai tertimbang dari matriks EFE sebesar 3,00 . Pertemuan antara sumbu $X$ dan sumbu $Y$ membentuk sumbu pusat yaitu $(2,98 ; 3,00)$. Berdasarkan kuadran SWOT ditunjukkan bahwa posisi LELEKU.Id Frozen Food terletak pada kuadran I. Dari posisi tersebut, usaha ini terletak pada posisi strategi SO (Kekuatan-Peluang) maka LELEKU.Id Frozen Food menggunakan strategi kekuatan internal untuk mengambil manfaat dari peluang. 


\section{Tahap Keputusan}

Tahap ini merupakan tahap akhir dari formulasi strategi. Tahap keputusan ini menggunakan matriks QSPM. Dari diagram kuadran tersebut alteratif prioritas strategi yang digunakan yaitu strategi SO (Kekuatan-Peluang). Matriks QSPM ini diawali dengan menentukan skor daya tarik (AS) dengan mengevaluasi setiap faktor internal dan eksternal kunci. Skor daya tarik berkisar antara 1-4. Skala penilaian daya tarik adalah $1=$ tidak menarik, 2=cukup menarik, 3=menarik, 4=sangat menarik. Langkah kedua yaitu menghitung skor daya tarik total (TAS) dengan cara mengalikan bobot tertimbang dengan AS. Diketahui ada dua alternatif strategi prioritas yaitu: (1) berinovasi dengan berbagai varian produk sebagai pertimbangan konsumsi konsumen dengan skor 4,03, (3) tidak menggunakan bahan berbahaya dan bisa dikonsumsi terus menerus dengan skor 3,91, dan (4) meminimalisir biaya bahan baku serta pengemasan agar tidak membutuhkan banyak biaya tambahan dengan skor 3,50.

\section{PENUTUP}

Berdasarkan hasil analisis melalui tiga tahap; tahap input (matriks IFE dan EFE), pencocokan (matriks SWOT), dan keputusan (QSPM) disimpulkan bahwa dalam tahap Input menggunakan (IFE dan EFE), pengukuran dari faktor internal (IFE) sebesar 2,98 dibulatkan menjadi 3 sehingga dapat dinyatakan bahwa faktor internal (kekuatan dan kelemahan) berpengaruh kuat terhadapproduk LELEKU.Id Frozen food dimana kekuatan utamanya ialah peniadaan bahan pengawet dalam produksi yaitu sebesar 0,64 dan kelemahan yang sangat berpengaruh dikarenakan minimnya pengalaman bidang pemasaran owner produk yaitu sebesar 0,64 .

Pengukuran dari faktor eksternal (EFE) sebesar 3 sehingga dapat dinyatakan bahwa faktor eksternal (peluang dan ancaman) berpengaruh kuat terhadap produk LELEKU.Id Frozen food di mana peluang utamanya ialah pangsa pasar yang cukup luas dengan nilai tertimbang sebesar 0,64 dan ancaman yang sangat berpengaruh dikarenakan produk yang dipasarkan tidak selalu ramai dengan nilai tertimbang sebesar 0,60. Setelah tahap input, dilanjutkan dengan tahap pencocokan. Pada tahap pencocokan, analisis Menerapkan matriks SWOT dengan mengombinasikan Kekuatan-Ancaman, Kelemahan-Ancaman, Kekuatan-Peluang, dan Kelemahan-Peluang menjadi sebuah strategi yang bertujuan untuk memperbaiki kualitas produk dan kinerja usaha di masa pandemi covid-19.

Tahap terakhir formulasi strategi yaitu keputusan dengan menggunakan matriks QSPM. Tahapan-tahapan tersebut kemudian menunjukkan strategi yang dapat digunakan untuk mempertahankan usaha LELEKU.Id Frozen food di saat pandemi Covid-19. Strategi yang dapat dipilih dengan prioritas berurutan sebagai berikut: berinovasi dengan berbagai varian produk, serta tidak menggunakan bahan berbahaya dan aman dikonsumsi. Hal ini secara tidak langsung dapat meningkatkan keunggulan bersaing antar UMKM di kondisi yang tidak menentu seperti saat ini.

\section{DAFTAR PUSTAKA}

Amalia A, Indah Y, Nanik K. (2020). Strategi Inovasi Terhadap Peningkatan Profit dimasa Pandemi Pada UMKM Our Mask. Journal of Accounting and Financial Issue, 61.

Baroto T, Purbohadiningrat C. (2014). Analisis Strategi Pengembangan Bisnis PPOB KIPO Menggunakan Analisis SWOT dan QSPM. Jurnal Teknik Industri, 15 No 1, 88-102.

David F R, David F R. (2017). Manajemen Strategic : Suatu Pendekatan Keunggulan Bersaing. Salemba Empat.

Fatimah F, Tyas W M. (2020). Strategi Bersaing IMKM rumah Makan di Saat Pandemi Covid 19. Jurnal Penelitian IPTEKS , 245-253. 
Juwono O. (2012). Analisis Manajemen Perusahaan Waralaba (Franchise) (Studi kasus di Restoran Cepat Saji McDonald's). Jurnal Ekonomika Dan Manajemen , 1-21.

Kusumastuti A D. (2020). Pengaruh Pandemi Covid-19 Terhadap Eksistensi Bisnis UMKM Dalam Mempertahankan Bussiness Continuity Management (BCM). Jurnal Administrasi Bisnis Fisipol Unmul, 224-232.

Luballu A O S. (2013). Strategi Bisnis Restoran Makanan Cepat Saji dengan Menggunakan Analisis SWOT (Studi Kasus Merek Rocket Chicken). Jurnal Ekomen , 42-61.

Mungkasa O. (2020). Bekerja dari Rumah (Working From Home/WFH): Menuju Tatanan Baru Era Pandemi COVID 19. Jurnal Perencanaan Pembangunan: The Indonesian , 126149.

Narto \& Basuki G. (2020). Penguatan Strategi Pemasaran Pudak di Tengah pandemi Covid 19 untuk Meningkatkan keunggulan Bersaing Usaha Mikro Kecil Menengah di Kota Gresik. Jurnal INTECH teknik Industri , 48-54.

Noor S. (2014). Penerapan Analisis SWOT dalam Menentukan Strategi Pemasaran Daihatsu Luxio di Malang. Jurnal INTEKNA , 102-209.

Nugroho A. (2020). Survei Kinerja UMKM di Masa Pandemi COVID 19. Retrieved from Lembaga Ilmu Pengetahuan Indonesia: http;//lipi.go.id/berita/survei-kinerja-umkm-dimasa-pandemicovid19/22071

Permata E G, Kusumanto I, Nur M \& Sijabat M N. (2019, November). Analisis Strategi Pemasaran dengan Menggunakan Metode SWOT dan Analytical Hierarchy Process (AHP) untuk Meningkatkan Volume Penjualan . Retrieved from http;//ejournal.uinsuska.ac.id/index.php/SNTIKI/article/view/7851

Rahmadi R, Soolany C \& Pratama A R. (2018). Penerapan Manajemen Strategi Pemasaran untuk Meningkatkan Daya Jual Produk UMKM Gula Merah di Kabupaten Cilacap. Jurnal rekayasa teknologi Industri Hijau, 1-6.

Rahmayati. (2015). Analisis SWOT dalam Menentukan Strategi Pemasaran Udang Beku PT. Mustika Nusa Tarakan, Kalimantan Utara. Jurnal galung Tropika , 1.

Ramadhan a \& Sofiyah F R. (2013). Analisis SWOT sebagau landasan dalam menentukan strategi pemasaran. Jurnal Media informasi Manajemen , 1-10.

Santoso I, Mustaniroh S A \& Pranowo D. (2018). Keakraban Produk dan Minat Beli Frozen Food. Jurnal Ilmu Keluarga \& Konsumen, 1-10.

Seputro A. (2019). Manajemen Strategi Dalam Pemberdayaan Ekonomi Bagi Masyarakat Menengah Kebawah Dalam Rangka Menangkal Paham Radikalisme Dan Terorisme Di Era Revolusi Industri 4.0. Jurnal Ekonomi Dan Bisnis Kontemporer , 1-21. 